\title{
JOURNEYING THEMES OF DATA MINING IN FELON AND LAW ENFORCEMENT AGENCY PROFILING
}

\author{
Apexa Lalitbhai Joshi ${ }^{1}$, Suresh M. B ${ }^{2}$ \\ ${ }^{I}$ Research Scholar, School of Science, R K University, Rajkot, Gujarat, India \& Assistant Professor JVIMS-MCA, \\ Jamnagar, Gujarat, India \\ ${ }^{2}$ Professor \& Head, Department of ISE, East West Institute of Technology, Bangalore, Karnataka, India
}

\begin{abstract}
Crimes are social nuisance and cost our society badly in several ways. Duties of federal agencies like federal and central bureau of investigation (FBI and CBI), police is to maintain law and order into countries crimes analysis and visualization mainly poor in the Indian police force. The reason behind that is poor and unclean data, missing electronic data is a common phenomenon in the developing countries like India. Police often have vast amount of least utilized crime data in the form of FIR (First Information Report) and subsequent inquiries reports of the particular case registered. If we analyzed reports could give us useful information to help in predicting the crime like crime committing trends, hidden information. To boost the efforts of police force we can use advance technology aspects of data mining for finding information and for visualizing in effective manner we apply GIS. In this paper if crime data is stored in computerized format then we will analyzed how data mining agencies in tracking the activities of criminals. But in developing country like India the major problem is unavailability of criminal data. Criminal or suspect data is not well documented. Once we have data in electronic techniques we are able to get analyzed data and statics more accurate when compare to manual system. In this paper were discuss the loo holes of existing system in India and purpose a new practical model that will provide us with efficiency, accuracy, drop in crime rate, suspect reorganization and provide us better society to live. It is possible with mathematical prediction and data mining techniques for analyzing and visualization.
\end{abstract}

Keywords: Knowledge discovery in database, crime, police, data mining prediction, GIS, hotspot, spatial analysis, finite differences

\section{INTRODUCTION}

In this digital epoch, police force gets access to a swiftly mounting amount of data. Due to the dynamic nature and complexity of the criminal activity it sets the scope for data mining applications. Regulation enforcement and intelligent agencies are facing challenge to analyses the bulky and complicated data involved in criminal tricks (Chen. Et al., 2003) [1].

In environments when data are poorly managed then we can apply various tricks of Geographical Information system and data mining tools to improve result that is proven by surveys as well. A structure consists of an incorporated data mining gadget called Data Detective, wide-ranging data warehouse containing data from diverse police systems and external sources like crime and criminal data, socio-demographics, geographical data and weather data etc.

By utilizing structure police officers can rapidly discover blueprints and fashions this make forecasts, find connections and probable explanations, chart criminal networks and recognize potential suspects. In addition, a much superior spectators for data mining outcomes are reached through weekly reports enclosed statistics, forecast maps, crime clusters, drifts and catalogues of suspects. These reports are robotically created by the data mining system.
In Section 2 we initiate by talk about why it is essential for police to pertain data mining, tag along by how vacant system will work in section 3 , roles of police department is discussed in the section 4 and deficiencies of time-honored systems in section 5. Sections 6 then express the system we have fabricate including how its practice is systematized and other assimilations in the section 7. In section 8 we discuss diverse benefits of the system. We finish with deliberations in section 9 and 10 about the appended value of data mining, the challenges for execution and future work.

\section{POLICE NECESSITATE FOR DATA MINIING}

Habitually police systems center of attention is on tiny elements of the on hand data like type of crime, month, and year for a precise reason for example keeping an eye on crime rates for tactic. Devoid of data mining, the quantity of data utilized in analysis is narrow by the time that forecaster have to go all the way through it, gradually. On the other hand, for countless policing tribulations it is significant to bring into play as much data as feasible, to be able to give details, appreciate, linkage and forecast. The justification of observable fact like the unexpected boost of pickpocket action typically lies in tiny facts, for example in the actuality that in the recent epoch Janmanstami festivals took place, with many probable pickpocket sufferers in to the particular region of city. 
Analyst reach to the right conclusions by using more contextual evidence, supplementary facts, pattern etc. like routine investigation require simple aspect of person and incident for mining more advance aspects are required to understand crime. Stolen goods, witness metaphors, MO or manner of working, background of the inhabitants involved in history vehicle engaged and countless additional attributes are there to analyze crime from different point view and for finding hidden facts.

Linking crimes by relationship also benefits in connect cases, detect crime series and solve them. Complication of criminal deeds, dynamic nature and handling the volume of data can be done by consuming the data mining techniques characteristics.

With the conventional techniques it is almost impossible to answer the questions related to crime location including area name, state country event co-ordinates where incident taken place. Time of the criminal activities performed day, time, month, year and week related information when criminal activities taken place. The solution of this entire problem is clever clustering techniques.

\section{VACANT STRUCTURE OF POLICE FORCE}

The police force is a state subject and not dealt with at central level according to article 246 of the Indian Constitution and section 3 of the IPA. Each state government has the responsibility to draw guidelines, rules and regulations for their respectively police forces. These regulations are found in the state police manuals [2].

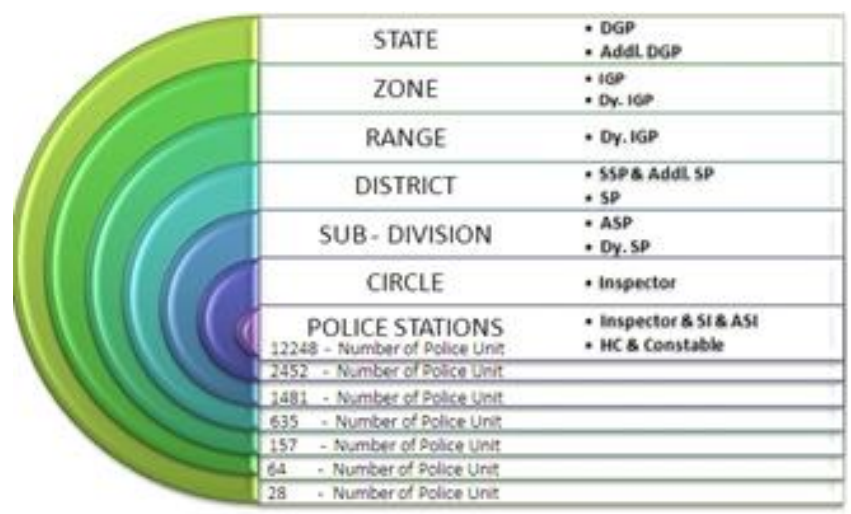

Fig -1: On 1.1.2002 the number of field units at different levels in the country

A state is divided into administrative police units. Highest in the hierarchy is the Director General of Police (DGP), who is the head of the state police force and is responsible for administration in the police and for advising the government on police issues. 8 With the DGP as highest responsible for the state police force, the state is divided into several Zones, Ranges and Districts. Further, the districts are separated into sub-divisions, circles and police stations. Each police station is responsible for a particular area, which they divide into beats and assign personnel to it. Nevertheless the structure is overall, strictly hierarchical and the decision making power is centralized with a few high ranking police officers [3].

\section{FUNCTIONS OF THE POLICE FORCE}

The functions of the police force in India are multifaceted. Section 23 of IPA lists the following function of the police force.

The basic role of force to assist the state territories in police operation to maintain law and orders. Returns to barracks once the objective achieved. Prevent the commission of offenders and public nuisances, riots control, crowd control, rescue and relief operations at the time of natural calamities, fighting aggression during war time, protection of VIPS, crime investigation, protection of state assets etc. The force is also being used for various police duties in various states. Every police station in a state is assigned an area where the police are upholding local law and order. Each area is in turn divided into different beats.

\section{LOOPHOLES OF EXISTING SYSTEM}

Traditional crime reporting system has several issues which are listed below:

\subsection{Below Standard Data Documentation}

Data are not stored in the electronic format. Records of crime and criminals are only available into the registers.

\subsection{Poor Fir Registering}

Just as it is a fact that police do not register many cases. Because of some personal benefit or in many cases the people do not report offences to the police. The reason behind that may be

- They felt that the offence was not serious enough.

- There was no use in reporting the matter to the police as the police could do nothing in the matter.

- $\quad$ They solve the problem them slaves

- Lodging of a report with the police was not considered appropriate

- $\quad$ The matter to the notice of police would lead to needless enmity between them and the offender

\subsection{Static Result}

Analytical techniques are not applied on data to find out hidden facts which can't be view from human eyes.

\subsection{Derived Awarness of Assets}

All officers are the assets to the department. There are no records available into the electronic format about how many police officers are there under one police chocki, case details, their detail qualification, minutes of the cases solved, gadgets available to the department etc. with the existing system information are not available into the eformat.

\subsection{Difficult Extractions}

All manual records are maintain at department level to carry out analysis relating, extraction, correction and ground work 
is necessary but is not possible with the manual system. Some old data might not available with department even. So the important extraction from data very hard to find.

\subsection{No Federal Bond among Various Departments}

All departments like CBI, FBI, police departments and lawyers are working on the same cases, but as per the current system there is no mechanism to inform each other about the things investigated or progress of the case. So it leads to unnecessary efforts on investigating the same things.

\subsection{Information Sharing \& Reporting to Higher}

\section{Authority is Nil}

Police officers teams are working on various cases there is no monthly, weekly or quarterly reporting system to their higher authority on the progress of the cases, who is working on them. So it is very difficult to track the progress.

If one case is solved in one jurisdictional area then that information is not shared among other police station. To get better and fast outcome in whole system sharing of solved cases details are not applicable at all. So by tacking that reference the result would be faster with lesser efforts.

High demands of mining application ([5] [6] [7] [8]) but the application developed are either academic endeavors or small applied projects - not continuous activities.

\section{NEW PROPOSED SYSTEM OVERVIEW}

In general most of the earlier papers from different author focused on the system related problems and their symptoms rather than on physical model matters. However to apply new technology to the system there has to be extensive change into physical model is required. Here is the discussion about novel proposed system structures which will be consist of information about assets of the department, law and order integrated, all cases information centrally managed on that electronic stored data set data mining techniques are applied.

As shown in the schematic overview below, local police force are define their own rule in some jurisdictional case and law and order are there to save them they actually insulting the crime investigation unit.

A local police force, oversight body, crime investigation unit, supervisory body and above all the collegiums are arranged in bottom up approach for reporting but without interference.

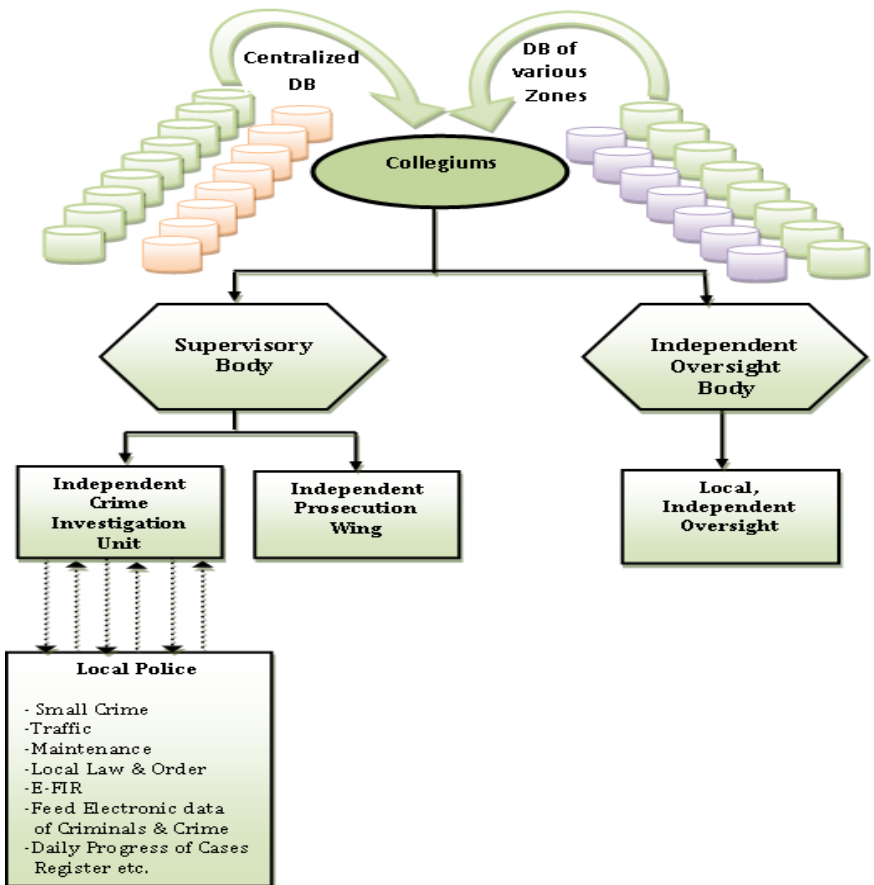

Fig -2: Proposed operational model of police force

\subsection{Crafting a Collegiums Supervisiory Body}

- Collegiums with Centralized Data Warehouses

States Eminent Personalities Chief Justice Of The High Court, State Chief Minister, Leaders Of The State Legislature And Home Minister Are The Part Of This Committee.

In The Current System Interference Of Higher Authority Is Very High To Reduce That State DGP Is Appointed For Tacking Responsibility Of Administrative Functioning.

All Cases Registered In Various Police Stations Their Case Solving Methodology And Person Involved In The Cases Are Stored Zone Wise And Centrally In Database. So, We Have Data To Analyze In Electronic Format.

- Supervisory Body

Creditable, Reputed And Experienced Domain Experts, Legal Experts, Professional Investigators And Jurist's Teams Are Working For The Department.

To Remove Administrative Interference With Promotions, Transfer And Appointments. All Wing Working In Their Own Way Independently. To Help Them A Team Of People Is There In The Team.

To Run Independent Working Of The Entire Department Without Any Political Force And Pressure.

\subsection{Self-Governing Crime Investigation Wing}

Legislative body is form to supervise the appointments of officers. For specific cases a team of officers are allocated. That decision is taken by the complexity and criticality of 
cases. Team head is appointed the experienced and specialized officer under that investigation officers are assign for investigating task on cases. The number of heads and investigation unit officers are depends on the case complication.

The reason behind changing the current working pattern is only remove external pressures and influences on the local investigation unit.

In majority grave offences like sexual offences, homicide, serious frauds, narcotics etc. are handled by local state police or investigation unit but result in unwarranted by external or political interference.

\subsection{Establishment of a Self-Governing Prosecution}

\section{Wing}

In order to give legal guidance crime investigation unit and prosecution wing cooperate closely. Supervisory body is responsible for the appointment of the key person in the wing. To give indecency from the district magistrates by the prosecution wing.

\subsection{Establishment of a Home-Grown Police Force}

P Daily task is assign to police force. A local police force in novel system will be working on jurisdiction function like local policing duties, traffic control and crimes. Some serious or grave offences are committed in that region then crime investigation team automatically take charge of that case. Each police man will have based on precise work description to do her work and task and designated role is assign. To achieve new team-oriented methodology.

\section{OVERVIEW OF MINING THEMES MATERIALIZE WITH NEW MODEL}

The following subcategory define the key procedures by utilizing that in practice of data mining.

\subsection{Where \& When Offences: Spatio-Temporal}

\section{Clusters}

Effective deployment of resources and allows proactive by knowing highest crime risk details. Some area suffer from burglaries in vacation time because many inhabitants are not at home, supermarkets and malls are crowded during rush hours and some area are crowed when schools and offices are closed. To search for a relations among all this situations or to find a pattern one could build an enormous cross table week, day and time of a week combine with region month and year which could be hard to interpret. More tactical planning is required to gather exact location information. It is impossible for police to prevent the crime if it happen in the same street further. Visual inspection and traditional method is not working if we require exact coordinate information. Offenders are not having the boundaries. So exact coordinates are required to catch them.

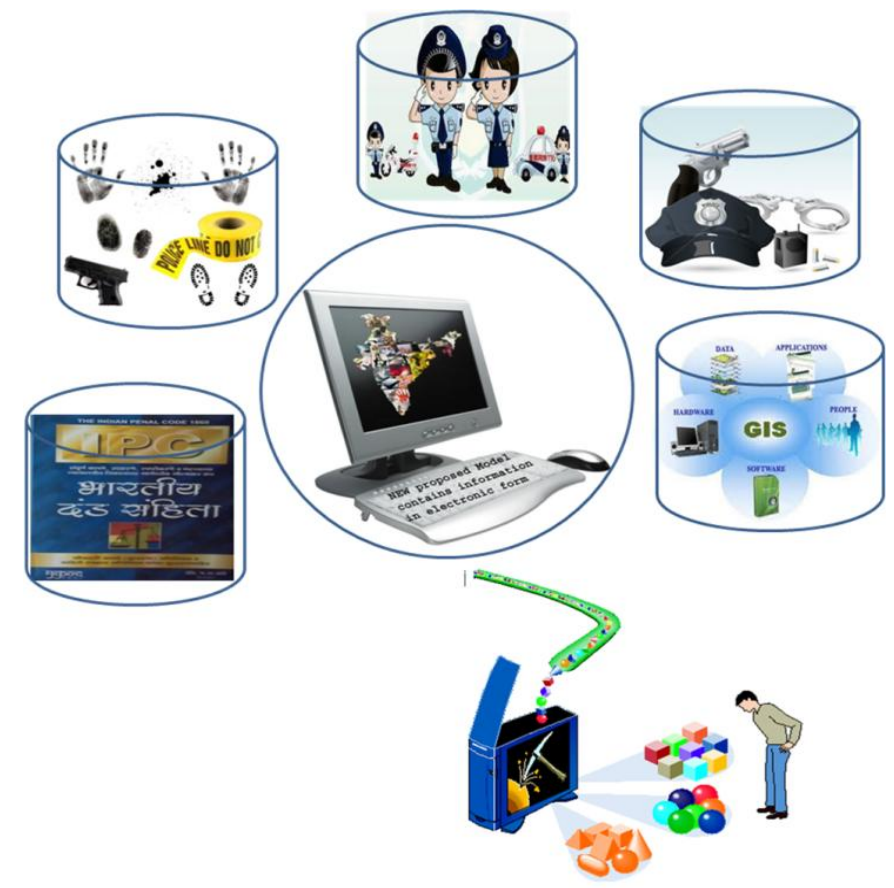

Fig -3: Various Tools for Better-off New System

Police officials have all the information together with the time and location when and where to go and what to do. Additional to this officials also have incident description and offender details. This is only possible with the popular approach of data mining techniques which hold all the information like similar incident from past, day, month and year of the incident, coordinates, time of the incident and current incident information.

Distance between two incidents are preserve into the associative memory with the help of the process. On this data metric multi-dimensional scaling [9] principle of associative cluster technique is applied. It generate the cluster result in two dimensions space or region. If we are looking for multi-dimensional result it leads to distortion. But 2D results are easy to interpret, visualize and finding relation among cluster for non-data mining experts or a laymen or non-technocrat.

Clustering algorithms $1^{\text {st }}$ step is to calculate the distance between 2 incidents via the help of associative memory. Based on this distance gravity forces are define: majority incidents are similar, dynamic nature. After this rotational forces are applied to finding moving object. If we apply iteration through optimization process then we get the cloud of similar instance. Priority crime types and continuous value in prevention is included in weekly report which is generated by system automatically. This reports shows a highlighted area, danger zones, list of clusters, region with graphical shape drown where the clusters are crime profile, description of time including day, week and year.

\subsection{Spatial Prediction: Associative}

To take general tactical decision like patrolling route for a week or month with time and space details can be find out with the help of spatio-temporal cluster for short period say 
for a particular day for $2-3$ hours shift optimal crime risk map is aimed to provide with the inclusion of the crime prediction method.

Future situation of predicated crime can be visualize by applying associative spatial prediction method. On past data stored into associative memory after this situations are used to form a detailed predictive hot spot map. This approach is on the prospective hot spotting [14], repeat victimization [10] [11] and routine activity [12] [13]. Only location is not consider in the associative spatial prediction we move a step ahead by considering other variables: day of a week, holidays, events, trends, weather and seasonal influences, festivals.

\subsection{Temporal Hot Spots}

For visualizing spatial patterns in time data mining using an approach temporal hot spots. A grid is created with the kernel density. A grid is a giving the density map as an output. Positive area shows the increased and negative area shows decreased rate of crime. But for that grid is subtracted value of KDG for recent and for past crime data.

\subsection{Geographic Profiling}

This method uses the locations of offences to find the native address or the area of offender [17]. Usually offender are not perform crime in their home addresses this theories are combined with activity radius of offender/felon. To restrict the region while solving a case probability map is created on activity theory with crime location this is robotically done based on data.

\subsection{Hot Spot Maps - Kernel Density Estimation}

Visualization of crime scene on map is optimal interpretation and crucial solution for officials. Plotting the crime dots on map is basic technique. If multiple crime is happen in nearby area then dots are more. So the map is filled with small and larger dots then interpretation of map is difficult because of clumsiness of dots. Interpolating incidents on map in cell of detailed grid and colored dot is result if hot-spot map. Map is also provide 3 levels of information with zooming facility is kernel density estimation [12] which is generally used. With single area larger number of cases registered to view that information exactly with address the extension of this method is required.

\subsection{Link Analysis}

Knowing relationship between criminal and crime is an important key to solve the cases. If we want to gather the information about criminal networks, relationships, roles, groups then we apply social network analysis theories. By applying this methodology it generate the chart of relationship among that criminal which is easier to visualize.

\subsection{Connected Suspect or Incidents}

When any problem comes then looking for various solutions which is taken by someone when they faces that problem. Accordingly to that when crime is performed what are the consequences taken by other officers in past to solve cases are search. But exact match of searched item done by associative search techniques. With criminal history with similar crime, witness description of criminal, scathes, same offender different crime.

\subsection{Series of Crimes: Cluster}

Analyst task is to find the relationship among solved cases finding groups or series of activities performed by single felon or groups. Linking is bases on suspect description, working pattern, weather, day and time. Linking is formed a clusters which is easily visualized to detect series. Because two dimensional chart are easily interpreted. To form charts associative clustering and self-organizing map [15] [16] is used. Kohonen maps gives faster output in minimum data requirements.

\subsection{Future Crime Prediction with Mathematical}

\section{Approch}

As with the advancement of the IT technologies, the amount of accumulated data is also increasing. It has resulted in large amount of data stored in databases, warehouses and other repositories. Thus the Data mining comes into picture to explore and analyze the databases to extract numeric prediction is known as Prediction. If we want to predict the next values outside the table then backward difference method is used. For prediction point precision, regression and Gregory - Newton backward interpolation method are analyzed out of this three technique Gregory - Newton backward interpolation is best suited for the crime data.

Crime data is taken from the ncrb website for the analysis the rate of crime for the next upcoming year. Here we have considered the year 2013 report based on this data we are able to analyzed the crime rate of year 2014. After finding the rate of crime for the year 2014 based on that again we can predict the crime for the year 2015. So that can help the police department to do the planning for the resources as well as patrolling schedules for reducing the crime from the society.

$$
\begin{aligned}
& \text { Observation we can express any value of y in terms of } \mathrm{y}_{\mathrm{a}} \text { and the backward differences } \mathrm{VV}_{\mathrm{I}}, \nabla^{2} \mathrm{y}_{\mathrm{g}} \text {, etc } \\
& \text { By definition } \quad \mathrm{y}_{\mathrm{n}}-\mathrm{y}_{\mathrm{n} \cdot 1}=\nabla_{\mathrm{n}} \\
& \text { Or } \quad \mathrm{y}_{\mathrm{n} \cdot 1}=\mathrm{y}_{\mathrm{n}} \cdot \nabla_{\mathrm{n}}=\left(1 \cdot \nabla_{\mathrm{n}} \mathrm{y}_{\mathrm{n}}\{1\}\right. \\
& \text { Now, } \quad \mathrm{y}_{\mathrm{n} \cdot 2}=\mathrm{y}_{\mathrm{n} \cdot 1} \cdot \nabla \mathrm{y}_{\mathrm{n} \cdot 1}=(1 \cdot \nabla] \mathrm{y}_{\mathrm{n} \cdot 1}=(1 \cdot 7)^{2} \mathrm{y}_{\mathrm{n}}[\text { Using ean }\{1\}] \\
& \text { Similarly, } \quad \mathrm{y}_{\mathrm{n} \cdot 3}=(1 \cdot \nabla)^{3} \mathrm{y}_{\mathrm{n}} \text { and so on. } \\
& \text { In general, } \quad V_{\mathbb{n} \cdot k}=(1-7)^{k^{y_{n}}} \quad\{2\} \\
& \underline{Y_{n} \cdot k}=y_{n}-k C_{1} \nabla y_{n}+k C_{2} \nabla y_{n} \cdot \ldots+(-1)^{k} \nabla k y_{n}
\end{aligned}
$$




\begin{tabular}{|c|c|c|c|c|c|c|}
\hline $\begin{array}{c}\delta \\
\text { Argument }\end{array}$ & $\begin{array}{l}Y=f(x) \\
\text { Entry }\end{array}$ & $\begin{array}{c}1^{\text {a }} \\
\text { Difference }\end{array}$ & $2^{2 \mathrm{si}}$ & Difference & $\begin{array}{c}4^{\mathrm{n}} \\
\text { Difference }\end{array}$ & $\begin{array}{c}5^{\mathrm{n}} \\
\text { Difference }\end{array}$ \\
\hline \multirow[t]{2}{*}{$\mathrm{x}_{0}$} & $y_{0}$ & & & & & \\
\hline & & $\nabla \mathrm{y}_{1}$ & & & & \\
\hline \multirow[t]{2}{*}{$\mathrm{x}_{\mathrm{l}}=\mathrm{x}_{0}+\mathrm{h}$} & $\mathrm{y}_{1}$ & & $\nabla_{y y_{2}}^{2}$ & & & \\
\hline & & $\nabla y_{2}$ & & $\nabla \cdot y_{3}$ & & \\
\hline \multirow[t]{2}{*}{$x_{2}=x_{0}+2 h$} & $y_{2}$ & & $\nabla^{2} \mathrm{y}_{3}$ & & $\nabla y_{4}$ & \\
\hline & & $\nabla y_{3}$ & & $\nabla \cdot y_{4}$ & & $\nabla^{\prime} y_{5}$ \\
\hline \multirow[t]{2}{*}{$x_{2}=x_{0}+3 h$} & $\mathrm{y}_{3}$ & & $\nabla^{2} \mathrm{y}_{4}$ & & $\nabla y_{5}$ & \\
\hline & & $\nabla y_{4}$ & & $\nabla \cdot y_{5}$ & & \\
\hline \multirow[t]{2}{*}{$\mathrm{x}_{\mathrm{A}}=\mathrm{x}_{0}+4 \mathrm{~h}$} & $y_{4}$ & & $\nabla^{2} y_{5}$ & & & \\
\hline & & $\mathrm{Vy}_{5}$ & & & & \\
\hline$x_{i}=x_{0}+5 h$ & $y_{5}$ & & & & & \\
\hline
\end{tabular}

Generalized formula for newton backward method:

$$
\begin{aligned}
& \mathrm{y}_{\mathrm{p}}=\mathrm{y}_{\mathrm{n}}+p \nabla \mathrm{y}_{\mathrm{n}}+\frac{\mathrm{p}(\mathrm{p}+1)}{2 !} \nabla^{2} \mathrm{y}_{\mathrm{n}}+\frac{\mathrm{p}(\mathrm{p}+1)(\mathrm{p}+2)}{3 !} \nabla^{3} \mathrm{y}_{\mathrm{n}}+\ldots \\
& +\frac{p(p+1)(\mathrm{p}+2) \ldots(\mathrm{p}+\mathrm{n}-1)}{\mathrm{n!}} \nabla^{\mathrm{n}} \mathrm{y}_{\mathrm{n}}[3]
\end{aligned}
$$

Where $\mathrm{y}_{\mathrm{k}}=\mathrm{y}\left(\mathrm{x}_{\mathrm{n}}+\mathrm{ph}\right)$, Equ(3) is known as Gregory- Newton backward interpolation formula.

For backward difference analysis involves a 2 variable, $\mathrm{x}$ and $\mathrm{y}$. Here for the analysis purpose $\mathrm{X}$ we have taken as the year and $y$ as a population after that in the second example we predict the rate of crime in the year 2014.Taken from ncrb website statistics-2013.pdf (page No: 22)

Table-1.1 incidence of Total Cognizable Crimes under

\begin{tabular}{|c|c|c|c|c|c|}
\hline $\begin{array}{l}X \\
\text { Argum } \\
\text { ent }\end{array}$ & $\begin{array}{l}\mathrm{Y}=\mathrm{f}( \\
\mathrm{x}) \\
\text { Entry }\end{array}$ & $\begin{array}{l}\text { 1st } \\
\text { Differen } \\
\text { ce } \\
\nabla y\end{array}$ & $\begin{array}{l}\text { 2nd } \\
\text { Differen } \\
\text { ce } \\
\nabla 2 y\end{array}$ & $\begin{array}{l}\text { 3rd } \\
\text { Differen } \\
\text { ce } \\
\nabla 3 y\end{array}$ & $\begin{array}{l}\text { 4th } \\
\text { Differen } \\
\text { ce } \\
\nabla 4 y\end{array}$ \\
\hline \multirow[t]{2}{*}{2009} & $\begin{array}{l}1169 \\
4\end{array}$ & & & & \\
\hline & & 164 & & & \\
\hline \multirow[t]{2}{*}{2010} & $\begin{array}{l}1185 \\
8\end{array}$ & & 80 & & \\
\hline & & 244 & & -292 & \\
\hline \multirow[t]{2}{*}{2011} & $\begin{array}{l}1210 \\
2\end{array}$ & & -212 & & 626 \\
\hline & & 32 & & 344 & \\
\hline \multirow[t]{2}{*}{2012} & $\begin{array}{l}1213 \\
4 \\
\end{array}$ & & 122 & & \\
\hline & & 154 & & & \\
\hline 2013 & $\begin{array}{l}1228 \\
8\end{array}$ & & & & \\
\hline
\end{tabular}
Indian Penal Code (IPC)

\begin{tabular}{|l|l|l|l|}
\hline Sr no & Year & $\begin{array}{l}\text { Projected Mid-Year } \\
\text { Population (In Lakh)* }\end{array}$ & Incidence \\
\hline 1 & 2003 & 10682 & 5494814 \\
\hline 2 & 2004 & 10856 & 6028781 \\
\hline 3 & 2005 & 11028 & 5026337 \\
\hline 4 & 2006 & 11198 & 5102460 \\
\hline 5 & 2007 & 11366 & 5733407 \\
\hline 6 & 2008 & 11531 & 5938104 \\
\hline 7 & 2009 & 11694 & 6675217 \\
\hline
\end{tabular}

\begin{tabular}{|l|l|l|l|}
\hline 8 & 2010 & 11858 & 6750748 \\
\hline 9 & 2011 & 12102 & 6252729 \\
\hline 10 & 2012 & 12134 & 6041559 \\
\hline 11 & 2013 & 12288 & 6640378 \\
\hline 12 & 2014 & 13524 & 8235067 \\
\hline
\end{tabular}

Table 1.2 Backward difference table for Year v/s Population

$\mathrm{Y}_{2014}=12288+154+122+334+626$ $=13524$

So here we can predict that the population for the year 2014 is 13524(lakh). This procedure is also performing for 2013 and the year 2012 from that values the differences 500 to 900 . But this prediction gives us nearby values.

\section{Backward difference table for Year v/s Rate of Crime}

\begin{tabular}{|l|l|l|l|l|l|}
\hline $\begin{array}{l}\text { Argum } \\
\text { ent }\end{array}$ & $\begin{array}{l}\text { Y=f(x } \\
\text { Entry }\end{array}$ & $\begin{array}{l}\text { 1st } \\
\text { Differe } \\
\text { nce } \\
\nabla y\end{array}$ & $\begin{array}{l}\text { 2nd } \\
\text { Differe } \\
\text { nce } \\
\nabla 2 \mathrm{y}\end{array}$ & $\begin{array}{l}\text { 3rd } \\
\text { Differe } \\
\text { nce } \\
\nabla 3 \mathrm{y}\end{array}$ & $\begin{array}{l}\text { Differe } \\
\text { nce } \\
\nabla 4 \mathrm{y}\end{array}$ \\
\hline 2009 & $\begin{array}{l}66752 \\
17\end{array}$ & & & & \\
\hline & & 75531 & & & \\
\hline 2010 & $\begin{array}{l}67507 \\
48\end{array}$ & & -573550 & & \\
\hline & & -498019 & & 860399 & \\
\hline
\end{tabular}




\begin{tabular}{|l|l|l|l|l|l|}
\hline 2011 & $\begin{array}{l}62527 \\
29\end{array}$ & -211170 & & 523140 & \\
\hline & & & & & \\
\hline 2012 & $\begin{array}{l}60415 \\
59\end{array}$ & & 809989 & & \\
\hline & & 598819 & & & \\
\hline 2013 & $\begin{array}{l}66403 \\
78\end{array}$ & & & & \\
\hline
\end{tabular}

$\mathrm{Y} 2014=6640378+598819+809989+523140+(-$ 337259)

$=8235067$

So here we can predict that the Rate of crime for the year 2014 is 8235067 (lakh). This procedure is also performing for 2013 and the year 2012 from that values the differences are there. But this prediction gives us nearby values.

\subsection{Aesthetic Outcome}

In majority tool if we provide longitude and latitude information then it will give the location. But if we analyze a person working with police department are not aware with the technical terms. So to make them useful and understandable here the map is used with plotted crime so that is easy to understand and take actions accordingly.

This is not only give us the state or city it gives us the location with street address and road number with FIR description so we are able to access all the information.

Google map is integrated with the system so both the view are provided satellite with label and map view for better visibility.

\section{FEATURES OF PROJECTED SYSTEM}

Proposed system is overcome the structural problems which is exist in the current system. Principles have been identified laid down the foundation of new system. New system has the following advantages.

- Continuous alert system for milestones to the officers for their cases.

- Reduce manual and redundant records keeping.

- Removed external political interference.

- Improved efficiency and reduced burden on officials.

- Collaboration with legal prosecution.

- Transparent system by automated functioning of department.

- Online registering of complaints.

- Informative report generation.

- Prediction of crime, places and criminal.

- Visualization and easy understanding to officials.

- Improved functioning.

- Sharing of information and guidance to the investigating officers.
- Daily, weekly, monthly and yearly report generation for tracking progress.

- Management improved with work assignment.

- Services are citizen- centric and improved through effective usage of advanced methodology of data mining.

\section{DISCUSSION}

As per the various articles frequently publish in newspapers support the statement that online FIR registering is possible in near future. Home minister is also spoke about the implementation of tracking system of crime and criminals.

All officials and police station link over a country with the pool of the intelligent system. As per the times of India cybercrime is upcoming challenge in front of the department.

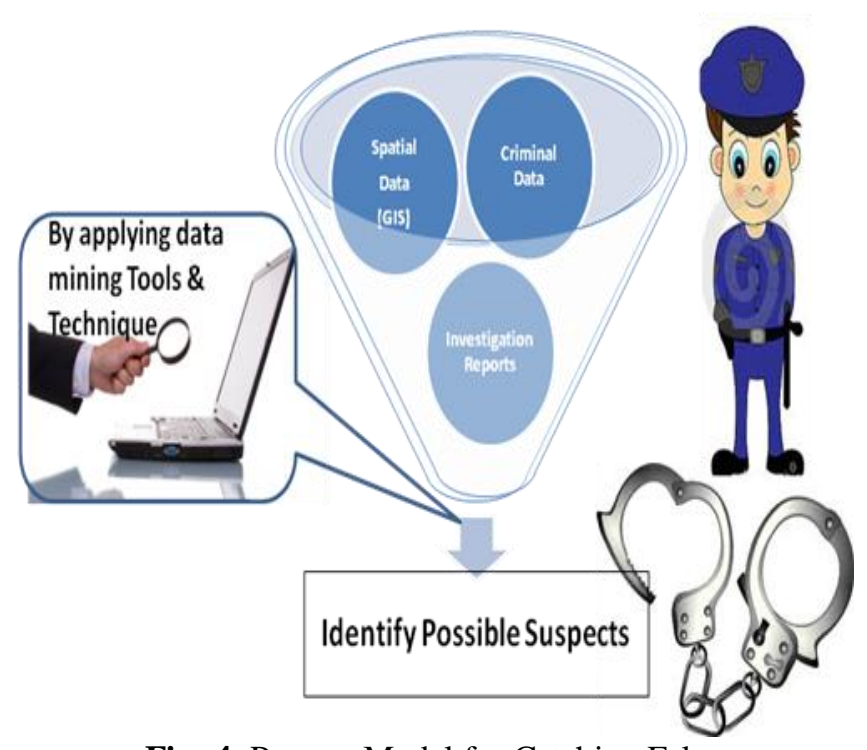

Fig -4: Process Model for Catching Felon

Utilization of output, spatial data and investigation reports boots the system and working with real time situation. Producing faster and effective services.

\section{FUTURE WORK}

Currently manual system is working in India after making them electronic operational new ideas are still there to making system better. New technology apply in new ways:

\subsection{Text}

Textual information plays important role in the system. As per the saying "garbage in garbage out". If input to the system is improper then no one is able to get solutions. Statement shave more details by utilizing that statement only extraction of entities are done like phone numbers, license plates, name and addresses. For case solving and linking people this entities and pattern analysis is done for gather information and relationship among entities. 


\subsection{Wealthy Representation}

In current system reports generation is offline and static. To give them dynamism that should be online. After making them online that data is shared among the department. For sharing network, cloud, databases and distributed environment can be used. Data should be in generalized format so HTML is converted in XML. Effective navigation of wealth of available report information.

\subsection{More Prediction Models}

This paradigms behavior and place of crime. Plenty of models are available in market. We listed some of them which are useful for criminal investigation.

Based on the situations and properties of that area day, time and weather the risk and occurrence of specific crime.

Based on socio-demographics, building and infrastructure prediction of crime rate.

Finding repeat offender by analyzing their career.

Domestic violence to give popularity to case and peoples involved in the case.

Preparation of criminal profile by analyzing parameter like gender, crime or series of crime, motive and age.

Based on personal profile and history risk of carrying and use of weapons tenure.

\section{CONCLUSION}

Day by day the rate of crime is increasing after the development. By implementing this model into practice we promise drop in crime rate. Which is boundless promise for the future.

In this paper we shows that data mining is a continuous or daily activity performed by police officials without extensive expertise in data mining and databases. Data mining is relatively difficult. Required domain expertize, difficult data extraction, data quality problems and analytical diversity. In proposed system this all difficulties are converted into the broadmindedness with co-ordination with police, automated algorithms, visualization of data, easy to use tool integration and large diverse data warehoused. This system is provide various levels analytical capacity in shorter time. By developing data mining techniques in proposed system become transparent, strong, faster and easy to use and lead to crime free society for betterment of the world.

\section{ACKNOWLEDGEMENTS}

We are thankful to all the people who directly and indirectly supporting in the learnings and findings. Our parents, all mighty, friend and all the author who give the guidance for further findings. All authority of the institutions for their support.

\section{REFERENCES}

[1]. Reza Fadaei-Tehrani, Thomas M. Green, (2002) "Crime and society'International Journal of Social Economics Volume 29 Number 10 pp. 781- 795.

[2]. Commonwealth Human Rights Initiative (n.d.) Police Reforms: India-Police Structure and Organisation (electronic source) retrieved August 18,2006 from http://www.humanrightsinitiative.org/programs/aj/police/ind ia/history/default.htm and "Report of the Review Committee on the Recommendations of National Police Commission \& Other Commissions/Committees on Police Reform" March 2005 , p. ii

[3]. "Police Organization in India" (Commonwealth Human Rights Initiative 2002) p. 8-13

[4]. See also N.S. Saksena's classification in Saksena, N.S. (2002) "Police and Politicians" Policing in India in the new millennium (editor P.J. Alexander 2002) p. 49, 50

[5]. McCue, C. 2007. Data mining and predictive analysis: Intelligence gathering and crime analysis, ButterworthHeinemann.

[6]. Mena, J. 2003. Investigative Data Mining for Security and Criminal Detection, Elsevier Science (USA).

[7]. Brown D.E. 1998. The Regional Crime Analysis Program (RECAP): A framework for mining data to catch criminals, University of Virginia.

[8]. Bruin, J.S. de, Cocx, T.K.., Kosters, W.A., Laros, J.F.J., Kok, J.N. 2006. Data Mining Approaches to Criminal Career Analysis, Proceedings of ICDM '06.

[9]. Borg, I. \& Groenen, P. 2005. Modern Multidimensional Scaling: theory and applications (2nd ed.), SpringerlVerlag New York.

[10]. Farrell, G. 2005. Progress and prospects in the prevention of repeat victimization.

[11]. Eck, J.E., Chainey, S., Cameron, J.G., Letiner, M. \& Wilson, R.E. 2005. Mapping crime: Understanding hot spots, Technical report 209393, National Institute of Justice. [12]. Chainey, S. \& Ratcliffe, J. 2005. GIS and Crime Mapping, Mastering GIS: Technology, applications and management, West Sussex, England: Wiley.

[13]. Clarke, R. V. \& M. Felson, Eds. 2004. Routine Activity and Rational Choice (Advances in Criminological Theory), Transaction Publishers, New Brunswick (U.S.A).

[14]. Bowers, K.J., Johnson, S.D. \& Pease, K. 2004. Prospective hot-spotting: The future of crime mapping? $\mathrm{Br}$. J. Criminol 44(5), pp. 641-658.

[15]. Kohonen, T. 1984. Self-organisation and associative memory, Springer series in information sciences, Vol8. Springer Verlag, New York, USA.

[16]. Adderley, R. \& P.B. Musgrove, P.B. 2001. Data Mining Case Study: Modeling the Behavior of Offenders Who Commit Serious Sexual Assaults, Proceedings of the seventh ACM SIGKDD international conference on Knowledge discovery and data mining.

[17]. Rossmo,D.K. 2000. Geographic profiling, Boca Raton, Fla, CRC Press.

[18]. International Journal of Computer Applications (0975 - 8887)Volume 21- No.1, May 2011

[19]. Freeman, L. 2004. The development of social network analysis, Vancouver, CA: Empirical Press. 


\section{BIOGRAPHIES}

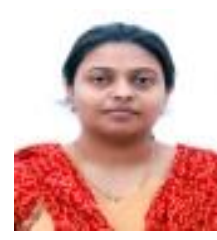

Ms. Apexa Lalitbhai joshi is a Ph.D. Scholar from R K University Rajkot in computer science. She is working as an assistant professor in MCA department at JVIMS - Jamnagar, Gujarat, India from last 7 years. Her area of specialization is data mining. She wrote national and international papers in various journals and conferences.

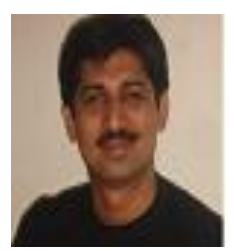

Dr. Suresh M. B. is a professor and head in ISE department at East West Institute of Technology in viswaneedam, Bangalore, Karnataka, India. He has having vast experience of 16 years in this filed. His area of specialization is digital image processing and his publication in international and national journals and conferences. He hold the professional membership of ISTE - LMISE. And he is guiding PH D students from various universities. 